\title{
Sumoylated RGS-Rz Proteins Act as Scaffolds for Mu-Opioid Receptors and G-Protein Complexes in Mouse Brain
}

\author{
María Rodríguez-Muñoz', David Bermúdez', Pilar Sánchez-Blázquez' and Javier Garzón*,' \\ 'Department of Neuropharmacology, Cajal Institute, CSIC, Madrid, Spain
}

\begin{abstract}
The RGSZI and RGSZ2 proteins, members of the RGS-Rz subfamily of GTPase-activating proteins (GAP), are involved in Mu-opioid receptor desensitization. The expression of these proteins, as well as of their main target the Gz protein, is virtually restricted to the nervous tissue. In synaptosomal membranes, these Rz proteins undergo post-translational modifications such as glycosylation and phosphorylation, and they may covalently attach to small ubiquitin-like modifier (SUMO) proteins. While RGSZI exists in conjugated and non-conjugated forms, RGSZ2 is mostly conjugated to SUMO-I, SUMO-2 and SUMO-3 proteins. These sumoylated forms of the GAPs readily associated with Mu-opioid receptors but they associated only poorly with Delta receptors. Furthermore, Gai2 and G $\alpha z$ subunits co-precipitated with the sumoylated forms of RGSZI/Z2 proteins, but to a lesser extent with the Ser phosphorylated SUMO-free form of RGSZI. Upon Mu-opioid receptor activation, there is a strong increase in the association of G $\alpha$ proteins with RGSZ2 proteins that persists for intervals longer than $24 \mathrm{~h}$. This effect probably accounts for their role in Mu-opioid receptor desensitization. Only a moderate increase was observed with RGSZI, the non-sumoylated form of which probably acts as an efficient GAP for these G $\alpha$ subunits. Therefore, sumoylation regulates the biological activity of RGS-Rz proteins and it is likely that it serves to switch their behavior, from that of a GAP for activated $\mathrm{G} \alpha$ subunits to that of a scaffold protein for specific signaling proteins.

Neuropsychopharmacology (2007) 32, 842-850. doi: I 0. I038/sj.npp. I 30 I I84; published online 9 August 2006
\end{abstract}

Keywords: SUMO; RGSZ-Rz proteins; Mu-opioid receptor; opioid desensitization; G-protein signaling; nervous tissue

\section{INTRODUCTION}

The regulators of G-protein signaling proteins (RGS) are GTPase-activating proteins (GAP) that bind to activated $\mathrm{G} \alpha \mathrm{GTP}$ subunits, accelerating the hydrolysis of GTP to GDP (Berman and Gilman, 1998). The expression of the Gz transducer proteins is limited to few organs/tissues such as the retina, nervous tissue, adrenal medulla, and platelets (Fong et al, 1988; Matsuoka et al, 1988; Gagnon et al, 1991). The $\mathrm{Rz}$ subfamily of RGS proteins efficiently deactivates receptor-activated GazGTP subunits (Glick et al, 1998; Wang et al, 1998; Mao et al, 2004). This RGS-Rz subfamily includes RGS17 (RGSZ2), RGS19 (GAIP: G $\alpha$ interacting protein), and two alternative splice variants, RGSZ1, and retinal RET-RGS1 (Ross and Wilkie, 2000). GAIP is found in a variety of tissues although it is not strongly expressed in the brain (De Vries et al, 1995; Grafstein-Dunn et al, 2001). In contrast, the expression of RGSZ1 and RGSZ2 is restricted almost completely to nervous tissue (Glick et al, 1998; Mao et al, 2004). These RGSZ2, GAIP, and RGSZ1

*Correspondence: Dr J Garzón, Neurofarmacología, Instituto Cajal, Avd Doctor Arce, 37, E-28002 Madrid, Spain, Tel: + 34 9I 585 4733, Fax: + 349 9 585 4754, E-mail: jgarzon@cajal.csic.es

Received 17 March 2006; revised 19 May 2006; accepted 6 July 2006 Online publication: 13 July 2006 at http://www.acnp.org/citations/ Npp07| 306060 I74/default.pdf proteins are of a moderate size, containing 210, 216, and 239 amino acids, respectively. They all have the RGS box, a conserved domain of approximately 120 residues that binds to the activated $G \alpha$ subunits to exert the GAP action. This common RGS box is flanked by a short C terminus of 12 amino-acid residues, and a cysteine string motif at the $\mathrm{N}$ terminus.

Neural RGS-Rz proteins isolated from synaptosomal membranes display different sizes (Garzón et al, 2004, 2005a) and while this may be due to splicing of the RGSZ1 gene (Barker et al, 2001), RGSZ2 does not appear to be subjected to such events (Mao et al, 2004). Thus, the different isoforms of these RGS-Rz proteins are more likely generated by post-translational modifications such as glycosylation. In fact, most of these protein isoforms can be found in the glycoprotein pool of neural membrane proteins and the action of $\mathrm{N}$ - and $\mathrm{O}$-glycosidases decrease their apparent molecular weight. Nevertheless, glycosidase action does not generate a homogeneous population and a ladder pattern is still observed (Garzón et al, 2004, 2005a). Therefore, RGS-Rz proteins may be subjected to other modifications in nervous tissue that also accounts for their diversity of size, and that probably influence their biological activity. Indeed, RGSZ1 and RGSZ2 proteins co-precipitate with $\mathrm{Mu}$-opioid receptors in mouse brain and they antagonize effectors by retaining $\mathrm{Mu}$-opioid receptor activated $\mathrm{G} \alpha \mathrm{i} 2$ and $\mathrm{G} \alpha \mathrm{z}$ subunits. This action plays an 
important role in promoting opioid desensitization (Garzón et al, 2004, 2005a). This phenomenon is not consistent with their GAP activity and could be promoted by interactions with other proteins that consequently impair this activity.

The Small Ubiquitin-like MOdifiers (SUMO) are proteins of about $12-15 \mathrm{kDa}$, that are covalently conjugated to proteins which containing the appropriate motifs. The activation of SUMO precursors, their conjugation and their release from target proteins is mediated by a series of specific enzymes (Melchior et al, 2003). The attachment of multiple SUMO molecules to target proteins, polysumoylation, leads to the formation of chains and these multiple protein isoforms are detected as a ladder pattern by SDSPAGE (Gocke et al, 2005). We show here that RGS-Rz proteins conjugate with SUMO-1/2/3 in synaptosomal membranes. Along with glycosylation, this modification accounts for the diverse sizes of RGS-Rz proteins that have been observed, and probably for switching their roles from that of a GAP to that of a scaffold protein facilitating now the sequester of $\mathrm{Mu}$-opioid receptor activated $\mathrm{G} \alpha$ subunits.

\section{METHODS}

\section{Preparation of Membranes and the Nuclear Fraction from Mouse PAG}

The study was performed using membranes isolated from periaqueductal gray matter (PAG), a neural structure that plays an important role in mediating the effects of opioids when administered by the icv route (Yaksh et al, 1976). Male albino CD-1 mice (Charles River, Barcelona, Spain) weighing 22-25g were used, from which PAG membranes enriched in synaptosomes were prepared as described previously (Garzón et al, 2005b). Briefly, 2 mm-thick coronal sections of the PAG from six mice were pooled in ice-cold $25 \mathrm{mM}$ Tris $\mathrm{HCl}(\mathrm{pH} 7.7), 1 \mathrm{mM}$ EGTA, $0.32 \mathrm{M}$ sucrose, protease inhibitor cocktail (Sigma, Madrid, Spain, \#P8340), phosphatase inhibitor mixture (Sigma, \#P2850) and H89 (Sigma, \#B1427). The tissue was homogenized (Polytron PT 10-35) and centrifuged at $1000 \mathrm{~g}$ for $10 \mathrm{~min}$ to remove the nuclear fraction. The pellet was saved and the supernatant was centrifuged at $20000 \mathrm{~g}$ for $20 \mathrm{~min}$ to obtain the synaptosomal pellet P2. After two cycles of washing, followed by resuspension in buffer and centrifugation, the final pellet was diluted in Tris buffer and used for the immunoprecipitation assays.

The initial pellet was resuspended in the same volume of homogenization medium and centrifuged again at $1000 \mathrm{~g}$ for $10 \mathrm{~min}$. The nuclear pellet was resuspended in five volumes of homogenization solution containing $2.3 \mathrm{M}$ sucrose and centrifuged at $50000 \mathrm{~g}$ for $60 \mathrm{~min}$ (Beckman TL-100, rotor TLA 100.1). The nuclei were obtained as transparent sediment at the bottom. The quality of the nuclear fraction was ascertained with antibodies against the nuclear envelope marker Lamin A (Abcam).

\section{Pull-Down Assays}

Affinity-purified IgGs against the signaling proteins under study were labeled with biotin (Pierce \#21217 and 21339). The procedure used to immunoprecipitate membrane proteins from the solubilized $\mathrm{P} 2$ fraction of mouse PAG has been described in detail (Garzón et al, 2005b). Briefly, for nondenaturing conditions about $1 \mathrm{mg}$ protein from $\mathrm{PAG}$ membranes was sonicated in $50 \mathrm{mM}$ Tris $\mathrm{HCl}(\mathrm{pH} 7.7)$, $50 \mathrm{mM} \mathrm{NaCl}, 1 \%$ Nonidet P-40, in the presence of protease and phosphatase inhibitors, and H89. The membranes were solubilized overnight at $4{ }^{\circ} \mathrm{C}$ and cleared with streptavidin agarose (Amersham, \#17-5113-01) pre-equilibrated for $1 \mathrm{~h}$ at $4{ }^{\circ} \mathrm{C}$, followed by centrifugation at $10000 \mathrm{~g}$ for $10 \mathrm{~min}$. The solubilized proteins were incubated overnight at $4{ }^{\circ} \mathrm{C}$ with the biotinylated IgGs raised against $\mathrm{G} \alpha \mathrm{z}, \mathrm{G} \alpha \mathrm{i} 2, \mathrm{Mu}-$ or Delta-opioid receptors, and the immunocomplexes were recovered with streptavidin agarose followed by centrifugation at $3000 \mathrm{~g}$. The agarose pellets were washed, centrifuged and resuspended in Nonidet P-40 buffer. The immune complexes were heated in a Tris- $\mathrm{HCl}, 1 \%$ sodium dodecyl sulfate buffer at $100^{\circ} \mathrm{C}$ to separate the IgG-agarose from the target protein and those that were associated with it. The agarose was separated in centrifugal filter devices with a $0.45 \mu \mathrm{m}$ pore (Ultrafree-MC \#UFC30GV, Millipore, Iberica, SA). The immunoprecipitated proteins were then concentrated in centrifugal filter devices $(10000 \mathrm{kDa}$ nominal molecular weight limit, Amicon Microcon YM-10 \#42407, Millipore), solubilized in Laemmli $2 \times$ buffers and resolved by SDS-PAGE. The proteins were transferred to $0.2 \mu \mathrm{m}$ polyvinylidene difluoride membranes for Western blot analysis and incubated with the antibodies in DecaProbe chambers (PR 150, Hoefer-Amersham Biosciences, Barcelona, Spain).

\section{SUMO and Phosphoserine Analysis of RGSZ1 ad RGSZ2 Proteins}

As unidentified proteins might coprecipitate with RGSZ1 and RGSZ2 proteins and interfere with the SUMO and phosphoserine analysis, the existing protein interactions were disrupted under denaturing conditions prior to performing immunoprecipitation. The PAG synaptosomal membranes were therefore heated in $40 \mathrm{mM}$ Tris $\mathrm{HCl}$, $1 \%$ SDS buffer for $10 \mathrm{~min}$ at $100^{\circ} \mathrm{C}$ in the presence of 2-mercaptoethanol. This mixture was then cooled to room temperature and the SDS concentration reduced by adding octylthioglucoside to a final percentage of $0.65 \%$. The immunoprecipitation of RGSZ1 and RGSZ2 proteins was then performed with the corresponding biotinylated IgGs and the procedure was continued as described above.

\section{Detection of Signaling Proteins}

The blots were probed with affinity purified rabbit IgGs against: RGSZ1 and RGSZ2 (Garzón et al, 2004, 2005a), $\mathrm{Mu}$ - and Delta-opioid receptors (Garzón et al, 2005d); G $\propto \mathrm{z}$ Helical domain (111-125) TGPAESKGEITPELL, G $\propto \mathrm{z}$ C-Terminus domain (346-355) QNNLKYIGLC, G $\alpha \mathrm{i} 2$ Helical domain (115-125) EEQGMLPEDLS (SánchezBlázquez et al, 1995; Garzón et al, 1997). Other antibodies used included: the mouse monoclonal antibody (IgM) to detect phosphoserines (Calbiochem, clone 1C8 525281); anti-GAIP C-terminus (goat) (sc-6207); anti-ubiquitin (Biomol, UG9510) (rabbit); anti-SUMO1 (Cell-Signaling, 4972) (rabbit); anti-SUMO2 C-terminus (sc-26973) (goat); anti-SUMO2/3 N-terminus (sc-26969) (goat). Primary antibodies were detected with goat anti-rabbit IgG $(\mathrm{H}+\mathrm{L})$ 
horseradish peroxidase conjugate antiserum (BioRad, \#1706515), a donkey anti-goat IgG horseradish peroxidase conjugate antiserum (sc2020), and a goat anti-mouse IgM $(\mathrm{H}+\mathrm{L})$ horseradish peroxidase conjugate antiserum (Calbiochem, 401225). The Westerns were all revealed with the $\mathrm{ECL}+$ plus Western Blotting Detection System (RPN2132, Amersham Biosciences), and the chemiluminescence was visualized with a ChemiImager IS-5500 (Alpha Innotech, San Leandro, CA, USA).

The assays were repeated twice on PAG samples obtained from independent groups of mice and the results were always comparable. Equal loading was verified in parallel blots generated with the same immunoprecipitated samples (Garzón et al, 2005a).

\section{Animals, Intracerebroventricular Injection and Evaluation of Antinociception}

Male albino CD-1 mice weighing 22-25 g were housed and used strictly in accordance with the guidelines of the European Community for the Care and Use of Laboratory Animals (Council Directive 86/609/EEC). Animals were kept at $22^{\circ} \mathrm{C}$ under a $12 \mathrm{~h}$ light/dark cycle (lights on from 0800 to 2000). Food and water were provided ad libitum. Animals were lightly anaesthetized with ether, and $10 \mathrm{nmol}$ morphine sulfate (Merck, Darmstadt, Germany) (in a volume of $4 \mu \mathrm{l})$ was injected into the lateral ventricle. The response of the animals to nociceptive stimuli was determined by the warm water $\left(52^{\circ} \mathrm{C}\right)$ tail-flick test. Antinociception was expressed as a percentage of the maximum possible effect $(\mathrm{MPE}=100 \times$ (test latency-baseline latency)/(cutoff time $\{10 \mathrm{~s}\}$-baseline latency)). To determine whether morphine produced tolerance, a test dose of $10 \mathrm{nmol}$ morphine identical to the priming dose was i.c.v. injected $24 \mathrm{~h}$ later into morphine-primed mice. Analgesia was then determined by the tail-flick test at various post-morphine intervals (further details as in Garzón et al, 2004, 2005a).

\section{RESULTS}

\section{RGS-Rz Protein Ladder Following SDS-PAGE}

The mRNAs encoding the RGS-Rz proteins RGSZ2, GAIP, and RGSZ1 are present in diverse structures of the mouse nervous system. After resolving these Rz proteins in SDSPAGE, a series of different sized isoforms were detected in a ladder pattern upon immunolabeling (Carrasco et al, 2004; Garzón et al, 2004, 2005a; Figure 1a). The size for the GAIP and RGSZ1 proteins corresponding to the murine aminoacid sequences were observed 25 and $27 \mathrm{kDa}$, respectively. However, the $24 \mathrm{kDa}$ RGSZ2 protein band was very weak, and the most intense bands were those of the higher molecular weights observed above $50 \mathrm{kDa}$ (Figure 1a).

\section{Sumoylation and Phosphorylation of RGS-Rz Proteins}

Computer-assisted analysis of the sequences of these $\mathrm{Rz}$ proteins (Center for Biological Sequence Analysis), predicted a high probability of glycosylation (http:// www.cbs.dtu.dk/services/NetNGlyc/Oglyc prediction Servers) and of serine phosphorylation at various residues (http://www.cbs.dtu.dk/services/NetPhos; http://myhits. isb-sib.ch/cgi-bin/motif_scan). In the mouse PAG synaptosomes, the different isoforms of RGSZ1 and RGSZ2 proteins are serine phosphorylated (Figure 2). It has been reported that the large $\mathrm{Rz}$ protein isoforms co-purify with the glycosylated fraction of synaptosomal membranes and the action of glycosidases increases their electrophoretic mobility in SDS-PAGE. However, some protein bands are still observed that are larger than the predicted sequences (Garzón et al, 2004, 2005a). Interestingly, members of this subfamily contain a motif that has a high probability of undergoing sumoylation (http://www.abgent.com/doc/ sumoplot): K121 in LKKE of RGSZ2; K127 in LKAE of GAIP; and $\mathrm{K} 150$ in LKRE of RGSZ1. In addition, RGSZ2 also contains a second potential sumoylation motif, K90 in MKTP. This common motif is found at the end of the helix $\alpha 4$ in each family member, at the beginning of the loop that connects $\alpha 4$ and $\alpha 5$ of the RGS domain. The second motif in RGSZ2 lies in helix $\alpha 3$.

In PAG synaptosomal membranes, antibodies directed against SUMO-1, SUMO-2, SUMO-2/3, as well as antibodies against the related modifier ubiquitin, all recognized a series of protein bands (not shown). Immunoprecipitation of RGSZ1 and RGSZ2 proteins from PAG synaptosomes revealed that they conjugated with SUMO-1, SUMO-2 and probably with SUMO-3, but not with ubiquitin. Indeed, antibodies against SUMO-1 and SUMO-2 recognized isoforms of RGSZ1 that were in the range of $50-55 \mathrm{kDa}$. SUMO-1 was also associated with a $75 \mathrm{kDa}$ isoform, while SUMO-2 was associated with isoforms of $60-65 \mathrm{kDa}$ (Figure 2a). Antibodies against SUMO-1, SUMO-2, and SUMO-2/3 recognized RGSZ2 proteins of about $60 \mathrm{kDa}$ and of $140 \mathrm{kDa}$ as well, while the SUMO-2 and SUMO-2/3 those of 43 and $80 \mathrm{kDa}$ (Figure 2b). Sumoylation and glycosylation probably contribute to increase the size of the smaller $24 \mathrm{kDa}$ RGSZ2 protein to $43 \mathrm{kDa}$ and above. It is probable that sumoylation of the RGS-Rz proteins occurred in the nucleus or in the nuclear pore complexes (Melchior et al, 2003), and that they were subsequently transported to the cell membrane. The presence of RGSZ2 and RGSZ1 in the nuclear fraction is consistent with this idea (Figure 3a).

\section{Sumoylated RGS-Rz Proteins Act as Scaffolds for Signaling Proteins in Synaptosomes}

In previous studies, we have shown that RGSZ1 and RGSZ2 co-precipitate with $\mathrm{G} \alpha$ subunits and $\mathrm{Mu}$-opioid receptors (Garzón et al, 2004, 2005a,c). Here, we show that these associations mostly involve the sumoylated forms of $\mathrm{Rz}$ proteins. The G $\alpha \mathrm{z}$ was immunoprecipitated with two antibodies, one directed against an epitope in the helical domain and the other raised against the $C$ terminus. Both antibodies co-precipitated a RGSZ2 isoform of about $43 \mathrm{kDa}$ that was recognized by SUMO-2/3, bands of $55-65 \mathrm{kDa}$ recognized by SUMO-1/2/3 (Figure $3 \mathrm{~b}$ ). The RGSZ2 band of $24 \mathrm{kDa}$ and those of higher molecular weights than $80 \mathrm{kDa}$ were only very weakly co-precipitated by these anti-G $\alpha \mathrm{z}$ antibodies. In contrast, an antibody directed to the helical domain of G $\alpha \mathrm{i} 2$ subunits co-precipitated RGSZ2 isoforms of 43, 65, 80 and $100 \mathrm{kDa}$. Weaker bands were also observed in the range $130-140 \mathrm{kDa}$. In the same synaptosomal fraction of the PAG, the Mu-opioid receptor co-precipitated various forms of the RGSZ2 protein (Garzón et al, 2005d). The most 
a

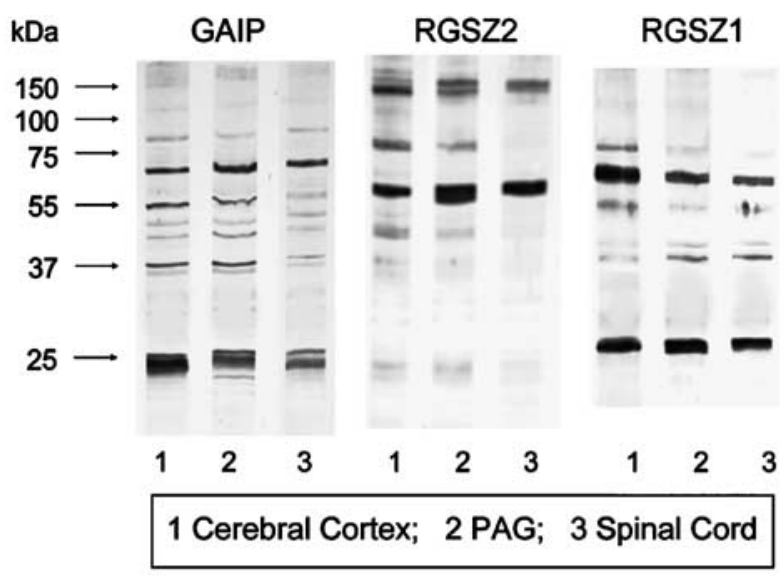

b

RGS17

RGS19

-

MRTANGGPRARASPSASPADPGLPEGSERTERRMRQMCGGSETQGPAPSQQGGR

23

RGS17 PNNTCCFCWCCCCSCSCLTVRNEERGDSSGRSPHTTKMESIQVLEECQNPTADEVLSWSO NFDK 87

RGS19 SRNPCCLCWCCCCSCSWNQERQRAWQVSRESKLQPLPSC-----EVCTPPSPKEVQSWAQ SFDK

RGS20 GSNACCFCWCCCCTCSCLTVRNQEDQRPQRASHEIRTD--IPACEESPTPTLEEVCAWAQ SFDN

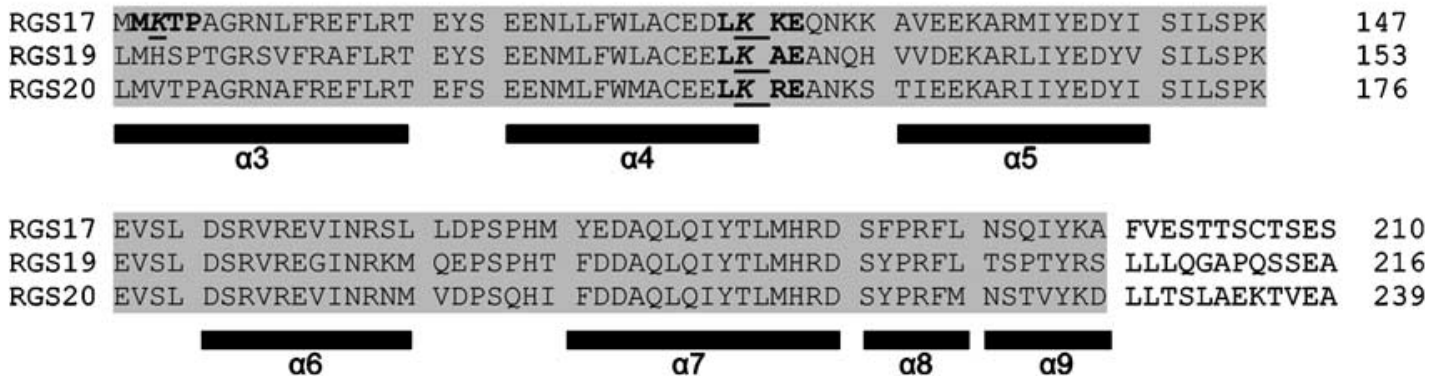

Figure I RGSZ-Rz proteins in mouse brain. (a), Mouse neural structures were collected and synaptosome enriched membranes were obtained. About $50 \mu \mathrm{g}$ of protein/lane were resolved by SDS-PAGE and transferred to PVDF membranes. Immunodetection was carried out with IgGs against GAIP, RGSZ2 and RGSZI as described in the Methods section. (b) Alignment of sequences of the murine RGS-Rz subfamily members. The cysteine rich domains are underlined, the RGS domains are shaded in gray and the $\alpha$-helical residues of their secondary structure are indicated using GAIP as template. The common sumoylation consensus motif is highlighted in bold, lysine in italics. For RGSZ2, a second putative SUMO conjugation site is also indicated. RGSI7(Z2) NP_64342; RGSI9(GAIP) NP_080722; RGS20(ZI) NP_067349.

intense of these bands were of $55-65 \mathrm{kDa}$ while weaker bands were identified at 80 and $130-140 \mathrm{kDa}$ (Figure $3 \mathrm{~b}$ ). Delta-opioid receptors did not appear to associate significantly with RGSZ2 (Figure $3 b$ ).

RGSZ1 was also co-precipitated with antibodies directed to $\mathrm{G} \alpha \mathrm{z} / \mathrm{i} 2$ subunits and $\mathrm{Mu} / \mathrm{Delta}$-opioid receptors. The RGSZ1 bands of 50-55 and 60-65 kDa were co-precipitated with G $\alpha$ z subunits, G $\alpha \mathrm{i} 2$ mostly associated with the RGSZ1 $60-65 \mathrm{kDa}$. Both $\mathrm{G} \alpha$ subunits co-precipitated the $27 \mathrm{kDa}$ non-sumoylated RGSZ1 form that is present in PAG membranes (Figures 1a, 4a). All the RGSZ1 forms that co-precipitated with the $\mathrm{G} \alpha$ subunits, including the nonsumoylated form, were seen to be serine phosphorylated (Figure $4 \mathrm{~b}$ ). The antibodies against the Mu-opioid receptor co-precipitated a principal $60-65 \mathrm{kDa}$ isoform of RGSZ1 and others at about $55 \mathrm{kDa}$. The Delta receptors only appeared to associate weakly with the RGSZ1 proteins and not at all when the assay was carried out on PAG membranes from $\mathrm{Mu}$-receptor null $(-I-)$ mice. As $\mathrm{Mu}$ - and Deltaopioid receptors are associated in mouse PAG membranes (Garzón et al, 2005d) it is possible that Delta receptors coprecipitate $\mathrm{Rz}$ proteins through their heterodimerization with other class(es) of receptors. In PAG synaptosomes from C57BL/6 Mu-opioid receptor null $(-/-)$ mice, virtually no RGSZ1/Z2 proteins co-precipitated with Delta receptors (Figures $3 b, 4 a)$.

Activation of the Mu-opioid receptor with an intracerebroventricular dose of morphine ( $10 \mathrm{nmol} /$ mouse) promoted the association of RGSZ2 proteins with Gai2 and G $\alpha z$ subunits (Figure 5a). The opioid promoted a much weaker association of the $\mathrm{G} \alpha$ subunits with the RGSZ1 proteins (Garzón et al, 2005a; Figure 5a).The increase in the co-precipitation of $\mathrm{G} \alpha$ subunits with RGSZ2 proteins peaked $30 \mathrm{~min}$ after opioid administration, the point at which morphine analgesia reaches a maximum when administered by this route. Notably, the association of 

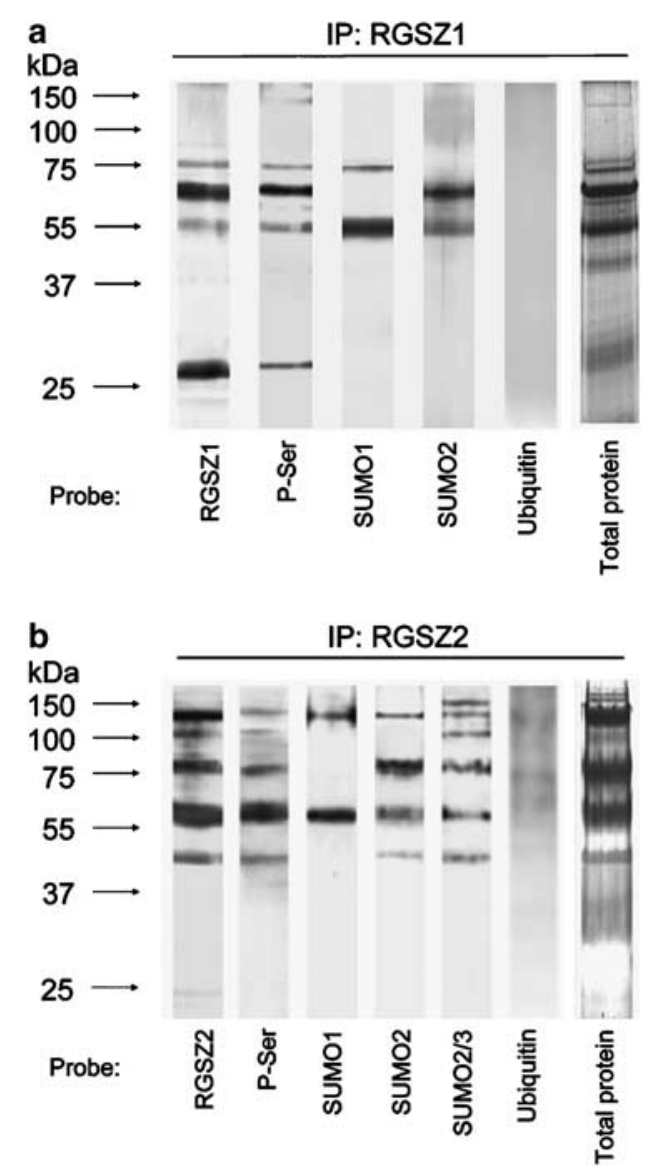

Figure 2 RGSZI/Z2 is sumoylated in PAG synaptosomal membranes. (a, b) PAG membranes were solubilized with SDS (denaturing conditions) as described in the Methods and the RGSZI and RGSZ2 proteins were immunoprecipitated and probed with antibodies against RGSZI/Z2, phosphoserine, ubiquitin and SUMO. The last lane shows the silver staining of proteins co-precipitated with RGSZI/Z2 antibodies from SDSsolubilized PAG membranes.

RGSZ2 with these subunits could still be observed at 3 and $24 \mathrm{~h}$ post-morphine injection when opioid no longer exerted an analgesic effect. The amount of the RGSZ2 proteins in PAG synaptosomes or their degree of sumoylation did not change in response to activation of $\mathrm{Mu}$-opioid receptors by morphine (Garzón et al, 2005d; Figure 5b). The sequestering of $\mathrm{Mu}$-receptor activated $\mathrm{G} \alpha \mathrm{z} / \mathrm{i} 2$ subunits by RGSZ2 proteins is thought to contribute to the desensitization observed when a second dose of morphine is administered $24 \mathrm{~h}$ after the first (Garzón et al, 2005a, Figure 5c). In all these assays, no proteins were co-precipitated with preabsorbed or heat-inactivated anti-Gai2/z, anti-RGSZ2/Z1 or anti-Mu-/Delta-opioid receptors IgGs.

\section{DISCUSSION}

When assayed in vitro, cloned RGSZ1 and RGSZ2 proteins display efficient GAP activity towards activated $\mathrm{G} \alpha \mathrm{i} / \mathrm{o} / \mathrm{z}$ subunits, and are the most efficient RGS in deactivating GazGTP subunits (Hepler et al, 1997; Glick et al, 1998; Wang et al, 1998; Mao et al, 2004). Typically, RGS proteins display greater affinity to binding to the so-called transition a

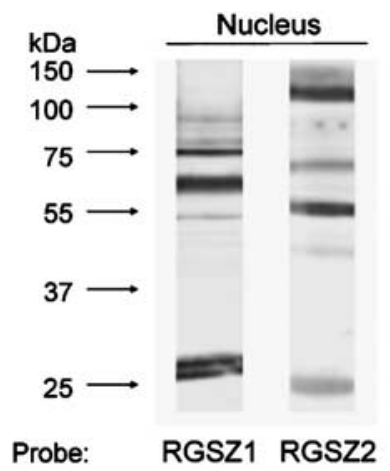

b

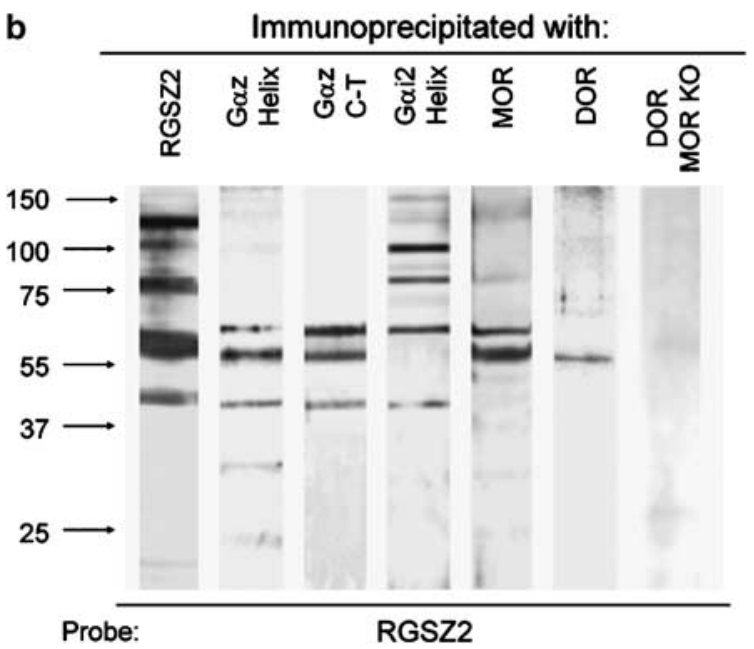

Figure 3 Co-precipitation of RGSZ2 proteins with Mu- and Deltaopioid receptors and G $\alpha z / i 2$ subunits. (a) RGSZI/Z2 immunoreactivity in the PAG nuclear fraction. (b) The pooled PAG synaptosomal membranes of $C D I$ mice were solubilized under nondenaturing conditions with $1 \%$ Nonidet P-40 and incubated overnight at $4^{\circ} \mathrm{C}$ with affinity-purified biotinylated IgGs raised against: extracellular domains of the $\mathrm{Mu}$ - and Delta-opioid receptors; the helical domain of G $\alpha z$ and Goi2 subunits; the G $\alpha z$ C Terminus. For the Delta receptor assays PAG membranes from C57BL/6 Mu-opioid receptor null (-/-) mice were also utilized. Immunocomplexes were precipitated with streptavidin agarose, resolved by SDS-PAGE and visualized in Western blots with antibodies directed against RGSZ2 proteins and phosphoserines.

state in which the conformation of the $\mathrm{G} \alpha$ is changed in order to initiate the conversion of the GTP into GDP (Berman et al, 1996; Hunt et al, 1996). However, the members of the RGS-Rz subfamily exhibit the distinctive feature of binding with similar affinities to the activated $\mathrm{G} \alpha \mathrm{GTP}$ subunits as well as to the transition state (Wang et al, 1997). This is accomplished through binding to the Nterminal helix of activated $\mathrm{G} \alpha$ subunits ( $\mathrm{Tu}$ et al, 1997; Wang et al, 1998), an interaction that is not observed between G $\alpha \mathrm{i}$ and RGS4 (Tesmer et al, 1997).

In the synaptosomal fraction, the RGSZ1 and RGSZ2 proteins show a series of post-translational modifications such as sumoylation, glycosylation, and phosphorylation, but not ubiquitination. These modifications indicate that the $\mathrm{Rz}$ proteins may behave in a more complex manner than simply acting as GAPs. Among these additional functions, they play a role in the sequestering of $\mathrm{G} \alpha \mathrm{z} / \mathrm{i} 2$ subunits that is triggered by morphine activation of $\mathrm{Mu}$-opioid receptors and persists long after the antinociceptive effects of the 
a
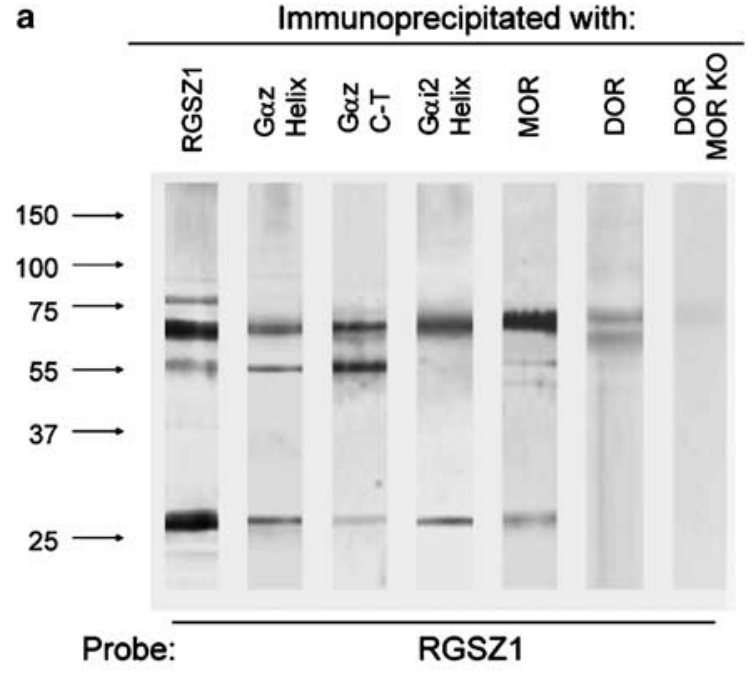

b IP with:

$\mathrm{G} \alpha \mathbf{z}$

Gai2

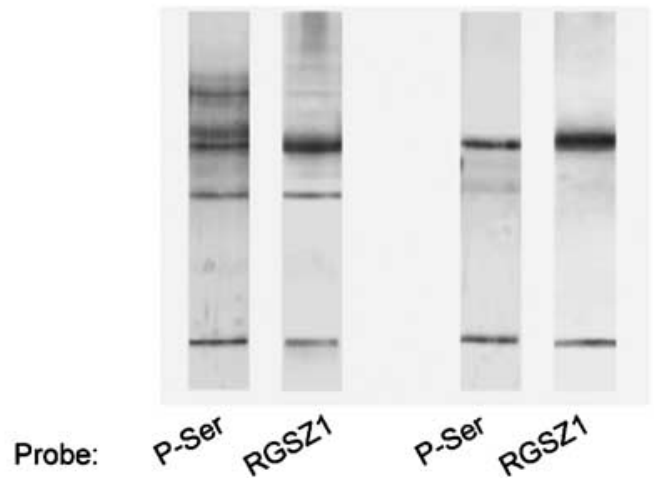

Figure 4 Association of RGSZI proteins with signaling proteins in PAG synaptosomal membranes. (a) Details as in the legend to Figure 3. (b) Membrane proteins co-precipitated with the helical domain of $G \alpha z$ and Gai2 subunits were solubilized with SDS and heated. After adding octylthioglucoside the immunoprecipitation of RGSZI was carried out, and serine phosphorylation of RGSZI isoforms was determined.

opioid have disappeared (Garzón et al, 2004). In these circumstances, $\mathrm{Rz}$ proteins work as scaffolds and SUMO conjugation could represent the switch for them to participate in this process. SUMO proteins are covalently linked to a variety of proteins and they appear to alter the long-term fate of the modified proteins even though they may be rapidly removed by SUMO-specific proteases. While SUMO-2/3 are $50 \%$ identical in sequence to SUMO-1 (Saitoh and Hinchey, 2000), only these SUMO-2/3 isoforms possess a consensus motif that can be utilized to form polymeric SUMO chains (Tatham et al, 2001). The machinery necessary for protein sumoylation is mostly nuclear (Melchior et al, 2003), although an increasing number of sumoylated proteins act outside the nucleus. These include cytosolic proteins such as $\alpha$-catenin, SCG10, phosducin (Gocke et al, 2005; Klenk et al, 2006), and the membrane spanning or attached proteins GLUT1 and GLUT4 transporters (Giorgino et al, 2000), or the focal adhesion kinase (Kadaré et al, 2003). It is therefore possible that these proteins are subject to nucleocytoplasmic cycling that facilitates their sumoylation in the nucleus and the subsequent redistribution to the cytosol and/or cell membrane. Thus, the presence of RGSZ1/Z2 proteins in the nuclear fraction probably reflects their sumoylation phase before they are transported to the neuronal membrane where palmitoylation of their $\mathrm{N}$ terminus cysteine string motifs (De Vries et al, 1996) and/or glycosylation (Garzón et al, 2004, 2005a) facilitates the targeting and signaling activity in this cellular compartment.

Whereas RGSZ1 and GAIP have a single motif with a high probability of sumoylation, RGSZ2 has two and this probably explains why it is difficult to detect the nonsumoylated form of RGSZ2. Phosphorylation could also account for the coexistence of the nonsumoylated and sumoylated forms of RGSZ1 and GAIP. Indeed, proteins like heat stress factor 1 must be phosphorylated to undergo efficient sumoylation (Hietakangas et al, 2003), although the contrary has been observed for the transcription factor c-Jun, the sumoylation of which is downregulated after phosphorylation (Müller et al, 2000). As sumoylation can be regulated by phosphorylation, it is possible that phosphorylation of critical residues on RGSZ1 impairs SUMO conjugation. The association of unmodified RGSZ1 proteins with activated $\mathrm{G} \alpha \mathrm{i} 2 / \mathrm{z}$ subunits could be rapidly disrupted by their GAP activity. However, impaired RGSZ1 GAP activity, probably due to phosphorylation of residues in the RGS domain (Garzón et al, 2005d), could promote the lasting association of these nonsumoylated RGSZ1 proteins with $\mathrm{G} \alpha$ subunits. In fact, the phosphorylated but not sumoylated form of RGSZ1 protein co-precipitated moderately with $\mathrm{G} \alpha \mathrm{Z}$ and $\mathrm{G} \alpha \mathrm{i} 2$ subunits.

The RGS box consists of nine alpha helices that form two subdomains, the $\mathrm{N}$-terminal and the bundle domain. Both are required for RGS binding to the transition state of $\mathrm{G} \alpha$ and for its subsequent GAP activity. The loops between $\alpha 3$ and $\alpha 4, \alpha 5$, and $\alpha 6$, and the residues at the end of $\alpha 7$ and at the beginning of the $\alpha 8$ helix form the G $\alpha$ interaction surface (Tesmer et al, 1997). Other RGS residues not involved in contact with $\mathrm{G} \alpha$ may mediate RGS-effector interactions, as occurs in the RGS9-1 and phosphodiesterase (PDE) $\gamma-\mathrm{G} \alpha \mathrm{t}$ complex. It has been proposed that above the RGS-G $\alpha$ interface, a series of residues cluster to form a potential site for additional proteins that could regulate RGS function (Sowa et al, 2000). The predicted common SUMO site for RGS-Rz proteins is located at the end of the RGS $\alpha 4$ helix, and the specific site in RGSZ2 is at the beginning of $\alpha 3$. Both these regions belong to this potential regulatory site; consistent with the idea that sumoylation may modulate protein-protein interactions (Matunis et al, 1998) and subcellular localization (Sobko et al, 2002). It is therefore possible that SUMO conjugation impedes or even disrupts the GAP activity of RGS-Rz proteins on receptor-activated $\mathrm{G} \alpha \mathrm{z} / \mathrm{i} 2$ subunits.

The sumoylated forms of RGSZ1/Z2 were more strongly associated with the $\mathrm{G} \alpha \mathrm{i} 2 / \mathrm{z}$ subunits and Mu-opioid receptors whereas they were substantially less strong associated with Delta-opioid receptors. This is in agreement with the failure of $\mathrm{Gz}$ and RGS-Rz proteins to regulate the effects of Delta agonists in the mouse brain (Garzón et al, 2004, 2005a). Activation of the $\mathrm{Mu}$ receptors produced a greater association of $\mathrm{G} \alpha \mathrm{i} 2 / \mathrm{z}$ subunits with RGSZ2 than with RGSZ1 (Garzón et al, 2005a). For the latter, it is probable that the unmodified form displays efficient GAP activity on these subunits, and that their association is then rapidly 


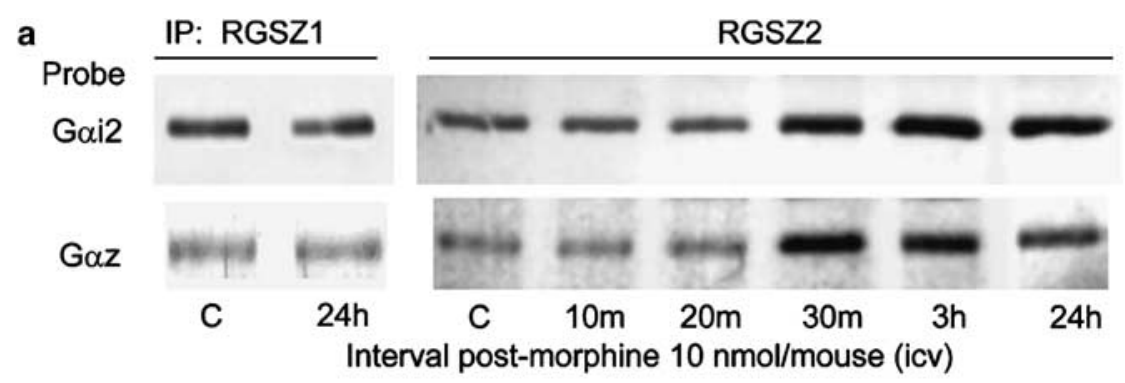

b

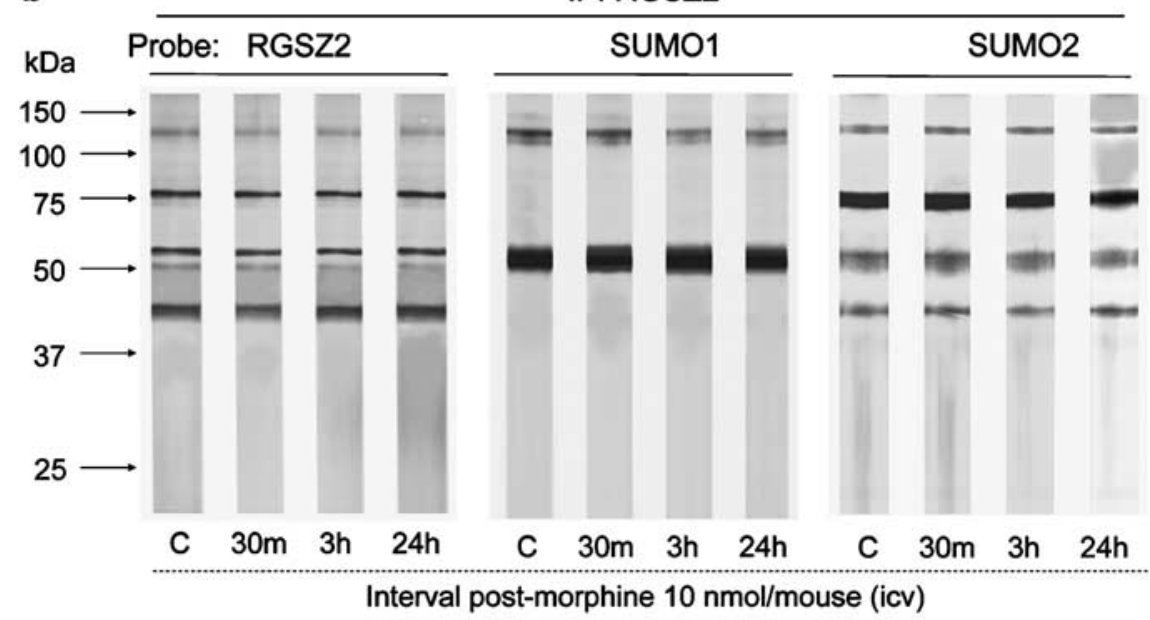

c

Morphine, $10 \mathrm{nmol}$

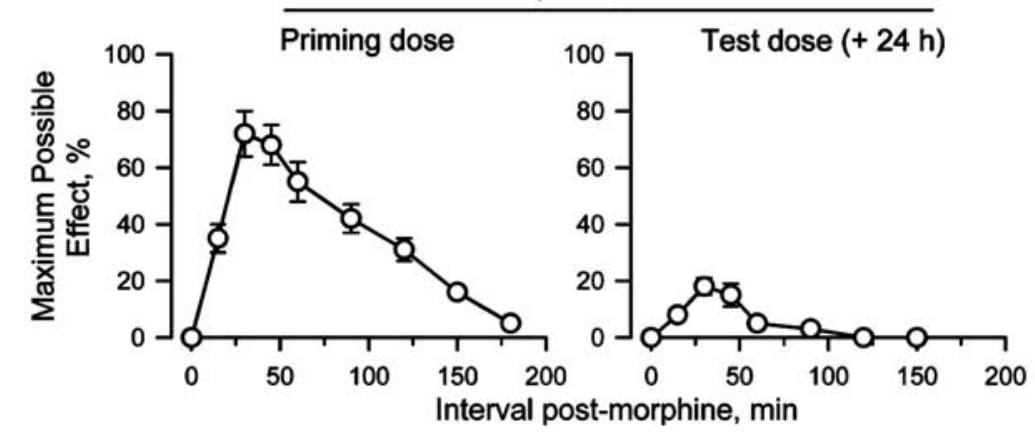

Figure 5 Co-precipitation of Mu-opioid receptor-activated $G \alpha$ subunits with RGSZI and RGSZ2 proteins. (a, b) A dose of I0 nmol morphine was injected i.c.v. into mice at various intervals before they were killed. PAG membranes were obtained; solubilized under nondenaturing conditions and the

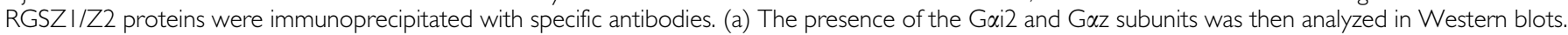
Equal loading was verified by probing anti-RGSZI/Z2 lgGs in parallel blots using the same immunoprecipitated material. (b) For each time interval studied the samples immunoprecipitated with RGSZ2 antibodies were divided into three equal fractions, they were resolved by SDS-PAGE and Western blots were probed with anti RGSZ2, anti-SUMOI, and anti SUMO2 antibodies. The experiments were conducted twice and comparable results were obtained on both occasions. (c) Animals were i.c.v.-injected with $10 \mathrm{nmol}$ morphine and the response of the animals to nociceptive stimuli was determined by the warm water $\left(52^{\circ} \mathrm{C}\right)$ tail-flick test. Antinociception was expressed as a percentage of the maximum possible effect. A test dose of morphine identical to the priming dose was injected i.c.v. $24 \mathrm{~h}$ later and the development of tolerance was observed by the reduction in antinociceptive potency.

disrupted. This was observed for RGSZ1 and Gaz subunits (Garzón et al, 2004). The activation of Mu-receptors did not promote changes of RGSZ2 proteins in the PAG nor did it alter their sumoylation. Hence, the increase in the association of RGSZ2-G $\alpha \mathrm{i} 2 / \mathrm{z}$ appears to be mostly facilitated by the segregation of the $\mathrm{G} \alpha$ subunits from $\mathrm{G} \beta \gamma$ dimers in response to morphine. The binding of RGS-Rz proteins to activated $\mathrm{G} \alpha$ subunits is thought to diminish their impact on the effectors and thus, to promote effector antagonism (Garzón et al, 2005c). Sumoylated RGSZ2 isoforms behave as scaffold for diverse signaling proteins (Garzón et al, 2005a; present work). Thus, sumoylated RGSZ2 forms not associated with the opioid receptor are mostly responsible for the sequestering of $\mathrm{Mu}$ receptor-activated $\mathrm{G} \alpha$ subunits, with a limited participation of those that co-precipitated with this receptor. This is indicated by the notable reduction of $\mathrm{G}$ proteins that co-precipitate with $\mathrm{Mu}$-opioid receptors following a morphine challenge (Garzón et al, $2005 a, b, c)$. The $G \alpha$ subunits that are now associated with the sumoylated RGSZ2 proteins could propagate signals initiated at the receptor, albeit through alternative signaling pathways. 
It is proposed that SUMO conjugation to RGSZ1/Z2 proteins alters their function from that of a GAP for activated $G \alpha$ subunits to that of a scaffolding protein for signaling elements such as $\mathrm{G} \alpha$ subunits and G-protein coupled receptors. Therefore, RGS-Rz sumoylation regulates the function of these receptors and probably endows the $\mathrm{G} \alpha$ subunits that are now in complex with them with new functions.

\section{ACKNOWLEDGEMENTS}

This work was supported by the grants SAF2003-01121 and SAF2005-01772. We are indebted to Dr Brigitte L Kieffer (University Louis Pasteur, Illkirch, France) for providing us with the C57BL/6 Mu-opioid receptor null $(-/-)$ mice.

\section{REFERENCES}

Barker SA, Wang J, Sierra DA, Ross EM (2001). RGSZ1 and Ret RGS: two of several splice variants from the gene RGS20. Genomics 78: 223-229.

Berman DM, Gilman AG (1998). Mammalian RGS proteins: barbarians at the gate. J Biol Chem 273: 1269-1271.

Berman DM, Wilkie TM, Gilman AG (1996). GAIP and RGS4 are GTPase-activating proteins for the Gi subfamily of $G$ protein alpha subunits. Cell 86: 445-452.

Carrasco GA, Barker SA, Zhang Y, Damjanoska KJ, Sullivan NR, Garcia $\mathrm{F}$ et al (2004). Estrogen treatment increases the levels of regulator of $\mathrm{G}$ protein signaling- $\mathrm{Z1}$ in the hypothalamic paraventricular nucleus: possible role in desensitization of 5hydroxytryptamine $_{1 \mathrm{~A}}$ receptors. Neuroscience 127: 261-267.

De Vries L, Elenko E, Hubler L, Jones TL, Farquhar MG (1996). GAIP is membrane-anchored by palmitoylation and interacts with the activated (GTP-bound) form of Gai subunits. Proc Natl Acad Sci USA 93: 15203-15208.

De Vries L, Mousli M, Wurmser A, Farquhar MG (1995). GAIP, a protein that specifically interacts with the trimeric $G$ protein G $\alpha \mathrm{i} 3$, is a member of a protein family with a highly conserved core domain. Proc Natl Acad Sci USA 92: 11916-11920.

Fong HK, Yoshimoto KK, Eversole-Cire P, Simon MI (1988). Identification of a GTP-binding protein $\alpha$ subunit that lacks an apparent ADP-ribosylation site for pertussis toxin. Proc Natl Acad Sci USA 85: 3066-3070.

Gagnon AW, Manning DR, Catani L, Gewirtz A, Poncz M, Brass LF (1991). Identification of $\mathrm{Gz} \alpha$ as a pertussis toxin-insensitive $\mathrm{G}$ protein in human platelets and megakaryocytes. Blood 78: 1247-1253.

Garzón J, Martínez-Peña Y, Sánchez-Blázquez P (1997). Gx/z is regulated by $\mu$ but not $\delta$ opioid receptors in the stimulation of the low Km GTPase activity in mouse periaqueductal grey matter. Eur J Neurosci 9: 1194-1200.

Garzón J, Rodríguez-Muñoz M, López-Fando A, García-España A, Sánchez-Blázquez P (2004). RGSZ1 and GAIP regulate $\mu$ - but not $\delta$-opioid receptors in mouse CNS: role in tachyphylaxis and acute tolerance. Neuropsychopharmacology 29: 1091-1104.

Garzón J, Rodríguez-Muñoz M, López-Fando A, Sánchez-Blázquez $P$ (2005a). The RGSZ2 protein exists in a complex with mu opioid receptors and regulates the desensitizing capacity of $\mathrm{Gz}$ proteins. Neuropsychopharmacology 30: 1632-1648.

Garzón J, Rodríguez-Muñoz M, López-Fando A, Sánchez-Blázquez $\mathrm{P}$ (2005b). Activation of Mu-opioid receptors transfers control of $\mathrm{G} \alpha$ subunits to the regulator of G-protein signaling RGS9-2. Role in receptor desensitization. J Biol Chem 280: 8951-8960.

Garzón J, Rodríguez-Muñoz M, De la Torre-Madrid E, SánchezBlázquez P (2005c). Effector antagonism by the regulators of $\mathrm{G}$ protein signalling (RGS) proteins causes desensitization of muopioid receptors in CNS. Psychopharmacology 180: 1-11.

Garzón J, Rodríguez-Muñoz M, Sánchez-Blázquez P (2005d). In mouse periaqueductal grey matter, morphine alters the selective association between Mu-opioid receptors and specific RGS proteins. Neuropharmacology 48: 853-868.

Giorgino F, de Robertis O, Laviola L, Montrone C, Perrini S, McCowen $\mathrm{KC}$ et al (2000). The sentrin-conjugating enzyme mUbc9 interacts with GLUT4 and GLU1 glucose transporters and regulates transporter levels in skeletal muscle cells. Proc Natl Acad Sci USA 97: 1125-1130.

Glick JL, Meigs TE, Miron A, Casey PJ (1998). RGSZ1, a Gzselective regulator of $G$ protein signaling whose action is sensitive to the phosphorylation state of Gza. J Biol Chem 273: 26008-26013.

Gocke GB, Yu H, Kang J (2005). Systematic identification and analysis of mammalian small ubiquitin-like modifier substrates. J Biol Chem 280: 5004-5012.

Grafstein-Dunn E, Young KH, Cockett MI, Khawaja XZ (2001). Regional distribution of regulators of G-protein signaling (RGS) $1,2,13,14,16$, and GAIP messenger ribonucleic acids by in situ hybridization in rat brain. Brain Res Mol Brain Res 88: 113-123.

Hepler JR, Berman DM, Gilman AG, Kozasa T (1997). RGS4 and GAIP are GTPase-activating proteins for $\mathrm{Gq} \alpha$ and block activation of phospholipase $\mathrm{C} \beta$ by $\gamma$-thio-GTP-Gq $\alpha$. Proc Natl Acad Sci USA 94: 428-432.

Hietakangas V, Ahlskog JK, Jakobsson AM, Hellesuo M, Sahlberg NM, Holmberg CI et al (2003). Phosphorylation of serine 303 is a prerequisite for the stress-inducible SUMO modification of heat shock factor 1. Mol Cell Biol 23: 2953-2968.

Hunt TW, Fields TA, Casey PJ, Peralta EG (1996). RGS10 is a selective activator of G $\alpha$ i GTPase activity. Nature 383: 175-177.

Kadaré G, Toutant M, Formstecher E, Corvol J-C, Carnaud M, Boutterin M-C et al (2003). PIAS1-mediated sumoylation of focal adhesion kinase activates its autophosphorylation. J Biol Chem 278: $47434-47440$.

Klenk C, Humrich J, Quitterer U, Lohse MJ (2006). SUMO-1 controls the protein stability and the biological function of phosducin. J Biol Chem 281: 8357-8364.

Mao H, Zhao Q, Daigle M, Ghahremani MH, Chidiac P, Albert PR (2004). RGS17/RGSZ2, a novel regulator of Gi/o, Gz and Gq signaling. J Biol Chem 279: 26314-26322.

Matsuoka M, Itoh H, Kozasa T, Kaziro Y (1988). Sequence analysis of cDNA and genomic DNA for a putative pertussis toxininsensitive guanine nucleotide-binding regulatory protein $\alpha$ subunit. Proc Natl Acad Sci USA 85: 5382-5388.

Matunis MJ, Wu J, Blobel G (1998). SUMO-1 modification and its role in targeting the Ran GTPase-activating protein, RanGAP1, to the pore nuclear pore complex. J Cell Biol 140: 499-509.

Melchior F, Schergaut M, Pichler A (2003). SUMO: ligases, isopeptidases and nuclear pores. Trends Biochem Sci 28: 612-618.

Müller S, Berger M, Lahembre F, Seeler J-S, Haupt Y, Dejean A (2000). c-Jun and p53 activity is modulated by SUMO-1 modification. J Biol Chem 275: 13321-13329.

Ross EM, Wilkie TM (2000). GTPase-activating proteins for heterotrimeric $G$ proteins: regulators of $G$ protein signalling (RGS) and RGS-like proteins. Ann Rev Biochem 69: 795-827.

Saitoh H, Hinchey J (2000). Functional heterogeneity of small ubiquitin-related protein modifiers SUMO-1 versus SUMO-2/3. J Biol Chem 275: 6252-6258.

Sánchez-Blázquez P, García-España A, Garzón J (1995). In vivo injection of antisense oligodeoxynucleotides to $\mathrm{G} \alpha$ subunits and supraspinal analgesia evoked by mu and delta opioid agonists. J Pharmacol Exp Ther 275: 1590-1596.

Sobko A, Ma H, Firtel RA (2002). Regulated SUMOylation and ubiquitination of DdMEK1 is required for proper chemotaxis. Dev Cell 2: 745-756. 
Sowa ME, He W, Wensel TG, Lichtarge O (2000). A regulator of G protein signaling interaction surface linked to effector specificity. Proc Natl Acad Sci USA 97: 1483-1488.

Tatham MH, Jaffray E, Vaughan OA, Desterro JMP, Botting $\mathrm{CH}$, Naismith JH et al (2001). Polymeric chains of SUMO-2 and SUMO-3 are conjugated to protein substrates by SAE1/SAE2 and Ubc9. J Biol Chem 276: 35368-35374.

Tesmer JJ, Berman DM, Gilman AG, Sprang SR (1997). Structure of RGS4 bound to AlF4-activated Gi 1 : stabilization of the transition state for GTP hydrolysis. Cell 89: 251-261.

Tu Y, Wang J, Ross EM (1997). Inhibition of brain Gz GAP and other RGS proteins by palmitoylation of $\mathrm{G}$ protein $\alpha$ subunits. Science 278: 1132-1135.
Wang J, Ducret A, Tu Y, Kozasa T, Aebersold R, Ross EM (1998). RGSZ1, a Gz-selective RGS protein in brain. Structure, membrane association, regulation by $\mathrm{G} \alpha \mathrm{z}$ phosphorylation and relationship to $\mathrm{Gz}$ GTPase-activating protein subfamily. J Biol Chem 273: 26014-26025.

Wang J, Tu Y, Woodson J, Song X, Ross EM (1997). A GTPaseactivating protein for the $G$ protein $G \alpha z$. Identification, purification, and mechsnism of action. J Biol Chem 272: $5732-5740$.

Yaksh TL, Yeung JC, Rudy TA (1976). Systematic examination in the rat of brain sites sensitive to the direct application of morphine: observation of differential effects within the periaqueductal grey. Brain Res 114: 83-103. 